\title{
Apolipoprotein A-IV Inhibits AgRP/NPY Neurons and Activates Pro-Opiomelanocortin Neurons in the Arcuate Nucleus
}

\author{
Chunling Yan ${ }^{a, e}$ Yanlin $\mathrm{He}^{\mathrm{a}}$ Yuanzhong Xuc Gang Shu ${ }^{\mathrm{a}, \mathrm{f}}$ Chunmei Wang ${ }^{\mathrm{a}}$ \\ Yongjie Yang $^{a}$ Kenji Saito ${ }^{a}$ Pingwen $\mathrm{Xu}^{\mathrm{a}}$ Antentor Othrell Hinton Jr. ${ }^{\mathrm{a}}$ \\ Xiaofeng Yan ${ }^{a}$ Likai Yu $^{\mathrm{a}, g}$ Qi Wu ${ }^{\mathrm{a}}$ Patrick Tso ${ }^{d}$ Qingchun Tong ${ }^{c}$ \\ Yong $\mathrm{Xu}^{\mathrm{a}, \mathrm{b}}$ \\ ${ }^{a}$ Children's Nutrition Research Center, Department of Pediatrics, Baylor College of Medicine, ${ }^{b}$ Department of \\ Molecular and Cellular Biology, Baylor College of Medicine, and 'Brown Foundation Institute of Molecular Medicine, \\ University of Texas Health Science Center at Houston, Houston, Tex., and ${ }^{\mathrm{d}}$ Department of Pathology and Laboratory \\ Medicine, University of Cincinnati, Cincinnati, Ohio, USA; ${ }^{\mathrm{e} M e d i c a l}$ College of Qingdao University, Qingdao, \\ fDepartment of Physiology, Institute of Animal Science, Southern China University of Agriculture, Guangzhou, and \\ gDepartment of Rheumatology, Union Hospital, Tongji Medical College of Huazhong University of Science and \\ Technology, Wuhan, China
}

\section{Key Words}

apoA-IV · Agouti-related peptide · Pro-opiomelanocortin . Arcuate nucleus · Electrophysiology · Food intake

\begin{abstract}
Background/Aims: Apolipoprotein A-IV (apoA-IV) in the brain potently suppresses food intake. However, the mechanisms underlying its anorexigenic effects remain to be identified. Methods: We first examined the effects of apoAIV on cellular activities in hypothalamic neurons that co-express agouti-related peptide (AgRP) and neuropeptide $Y$ (NPY) and in neurons that express pro-opiomelanocortin (POMC). We then compared anorexigenic effects of apoA-IV in wild-type mice and in mutant mice lacking melanocortin 4 receptors (MC4Rs; the receptors of AgRP and the POMC
\end{abstract}

Chunling Yan and Yanlin He contributed equally to this work.

\section{KARGER}

(C) 2015 S. Karger AG, Base

0028-3835/15/1035-0476\$39.50/0

E-Mail karger@karger.com

www.karger.com/nen gene product). Finally, we examined expression of apoA-IV in mouse hypothalamus and quantified its protein levels at fed versus fasted states. Results: We demonstrate that apoA-IV inhibited the firing rate of AgRP/NPY neurons. The decreased firing was associated with hyperpolarized membrane potential and decreased miniature excitatory postsynaptic current. We further used c-fos immunoreactivity to show that intracerebroventricular (i.c.v.) injections of apoAIV abolished the fasting-induced activation of AgRP/NPY neurons in mice. Further, we found that apoA-IV depolarized POMC neurons and increased their firing rate. In addition, genetic deletion of MC4Rs blocked anorexigenic effects of i.c.v. apoA-IV. Finally, we detected endogenous apoA-IV in multiple neural populations in the mouse hypothalamus, including AgRP/NPY neurons, and food deprivation suppressed hypothalamic apoA-IV protein levels. Con- 
clusion: Our findings support a model where central apoAIV inhibits AgRP/NPY neurons and activates POMC neurons to activate MC4Rs, which in turn suppresses food intake.

(c) 2015 S. Karger AG, Basel

\section{Introduction}

Apolipoprotein A-IV (apoA-IV) is a major protein component of intestinal triacylglycerol-rich lipoproteins such as chylomicrons and very low-density lipoproteins. Circulating apoA-IV stems from the intestine and the liver [1]. The functions of circulating apoA-IV have been primarily related to protection from cardiovascular disease due to its well-characterized antioxidative and antiinflammatory properties [2].

Evidence indicates that apoA-IV also regulates feeding behavior. Central administration of apoA-IV in rats suppresses food intake without signs of toxicity, while blockade of brain apoA-IV by a neutralizing antibody increases food intake in rats [3]. Importantly, mice with global deficiency in the apoA-IV gene show enhanced refeeding response after food deprivation [4], arguing a physiological role of apoA-IV in the control of feeding behavior. Although the anorexigenic effects of central apoA-IV become increasingly appreciated [2], little is known about where and how apoA-IV regulates feeding behavior.

The central melanocortin system is comprised of neurons which produce endogenous melanocortins and the downstream neurons that express melanocortin receptors, such as melanocortin 4 receptors (MC4Rs) [5]. The melanocortin neurons include those expressing pro-opiomelanocortin (POMC) and those co-expressing agoutirelated peptide (AgRP) and neuropeptide $\mathrm{Y}$ (NPY), which are both located in the arcuate nucleus of the hypothalamus (ARH). On one hand, POMC neurons synthesize and secrete $\alpha$-melanocyte-stimulating hormone to activate MC4Rs, which in turn leads to suppression of food intake. On the other hand, AgRP/NPY neurons release orexigenic peptides AgRP and NPY. In particular, AgRP functions as the inverse agonist of MC4Rs and promotes food intake. NPY also strongly stimulates food intake via NPY receptors [6]. POMC and AgRP/NPY neurons have been long believed to be the primary central regulators of feeding behavior and energy homeostasis $[7,8]$.

Pharmacological evidence suggests that the central melanocortin system may be involved in the anorexigenic effects of apoA-IV [9]. Here, we first combined genetic reporter mouse models and the electrophysiological approaches to examine the effects of apoA-IV on the cellular activity of AgRP/NPY and POMC neurons in the ARH. The in vitro electrophysiological results were further validated using c-fos immunostaining in vivo. In addition, we determined if genetic deletion of MC4Rs in mice could block anorexigenic effects of central administration of apoA-IV. Finally, we detected endogenous apoA-IV protein in mouse hypothalamus and determined if apoA-IV levels in the hypothalamus were regulated by nutritional states.

\section{Methods}

Mice

A number of genetically modified mouse models were used in the current study. First, we bred AgRP-IRES-Cre mice [10] to Rosa26-tdTOMATO mice [11] (obtained from Jackson Laboratory, No. 007905) to generate AgRP-IRES-Cre/Rosa26-tdTOMATO mice. Similarly, we bred POMC-CreER mice [12] to Rosa26-tdTOMATO mice to generate POMC-CreER/Rosa26-tdTOMATO mice; these mice receive an i.p. injection of tamoxifen $(0.2 \mathrm{mg} / \mathrm{g}$, at 6 weeks of age) to induce Cre activity specifically in POMC neurons. Both these AgRP-IRES-Cre/Rosa26-tdTOMATO and POMC-CreER/ Rosa26-tdTOMATO mice were used for electrophysiology studies described below. We also crossed NPY-GFP mice [13] (obtained from Jackson Laboratory, No. 008321) with C57Bl6 mice to produce NPY-GFP mice, which were used for c-fos study as described below. In addition, we crossed heterozygous MC4R-null (loxTB-MC4R) mice [14] to generate homozygous MC4R-null mice and their wildtype (WT) littermates for feeding studies. All the breeders have been backcrossed to C57Bl6 background for more than 12 generations. In addition, some C57Bl6 mice were purchased from the mouse facility of Baylor College of Medicine.

Mice were housed in a temperature-controlled environment at $22-24^{\circ} \mathrm{C}$ using a 12 -hour light/12-hour dark cycle. The mice were fed ad libitum with standard chow (6.5\% fat, No. 2920; HarlanTeklad, Madison, Wis., USA), unless mentioned otherwise. Water was provided ad libitum. All mice experiments were approved by the Institutional Animal Care and Use Committee of Baylor College of Medicine at Houston.

\section{Electrophysiology}

Whole-cell patch clamp recordings were performed on TOMATO-labelled neurons (AgRP/NPY neurons or POMC neurons) in the ARH-containing hypothalamic slices from AgRPIRES-Cre/Rosa26-tdTOMATO mice or from POMC-CreER/Rosa26-tdTOMATO mice. Six- to 12-week old mice were deeply anesthetized with isoflurane in early morning with or without an overnight fast and transcardially perfused with a modified ice-cold sucrose-based cutting solution (adjusted to $\mathrm{pH} 7.3$ ) containing (in mM) $10 \mathrm{NaCl}, 25 \mathrm{NaHCO}_{3}, 195$ sucrose, 5 glucose, $2.5 \mathrm{KCl}, 1.25$ $\mathrm{NaH}_{2} \mathrm{PO}_{4}, 2 \mathrm{Na}$ pyruvate, $0.5 \mathrm{CaCl}_{2}, 7 \mathrm{MgCl}_{2}$ bubbled continuously with $95 \% \mathrm{O}_{2}$ and $5 \% \mathrm{CO}_{2}$, as we have done before [15]. The mice were then decapitated, and the entire brain was removed and immediately submerged in ice-cold sucrose-based cutting solution. Using a Microm HM 650V vibratome (Thermo Scientific), the brains were cut into coronal slices (without trimming at other dimension) at a thickness of $250 \mu \mathrm{m}$ each. Usually, 3-4 consecutive 
brain slices per mouse, ranging from bregma -2.54 to $-1.46 \mathrm{~mm}$, contained the ARH, and adjacent nuclei (the ventromedial hypothalamus, the dorsal medial hypothalamus and the lateral hypothalamus) were used for recordings. The slices were recovered for $1 \mathrm{~h}$ at $34^{\circ} \mathrm{C}$ and then maintained at room temperature in artificial cerebrospinal fluid (aCSF; adjusted to $\mathrm{pH} 7.3$ ) containing (in $\mathrm{mM}$ ) $126 \mathrm{NaCl}, 2.5 \mathrm{KCl}, 2.4 \mathrm{CaCl}_{2}, 1.2 \mathrm{NaH}_{2} \mathrm{PO}_{4}, 1.2 \mathrm{MgCl}_{2}, 11.1$ glucose and $21.4 \mathrm{NaHCO}_{3}$ ) saturated with $95 \% \mathrm{O}_{2}$ and $5 \% \mathrm{CO}_{2}$ before recording. For some recordings, slices were recovered in aCSF containing $4 \mathrm{~mm}$ glucose which better mimic the physiological glucose levels in the brain. As shown in figure 1, results obtained from $11.1 \mathrm{~mm}$ glucose and $4 \mathrm{~mm}$ glucose aCSF were comparable.

Slices were transferred to the recording chamber and allowed to equilibrate for at least $10 \mathrm{~min}$ before recording. The slices were superfused at $34^{\circ} \mathrm{C}$ in oxygenated aCSF at a flow rate of $1.8-2 \mathrm{ml} / \mathrm{min}$. TOMATO-labelled neurons in the ARH were visualized using epifluorescence and IR-DIC imaging on an upright microscope (Eclipse FN-1; Nikon) equipped with a moveable stage (MP-285; Sutter Instrument). Patch pipettes with resistances of 3-5 M $\Omega$ were filled with intracellular solution (adjusted to $\mathrm{pH} 7.3$ ) containing (in $\mathrm{mM}) 128 \mathrm{~K}$ gluconate, $10 \mathrm{KCl}, 10 \mathrm{HEPES}, 0.1 \mathrm{EGTA}, 2 \mathrm{MgCl}_{2}, 0.05$ $\mathrm{Na}-\mathrm{GTP}$ and $0.05 \mathrm{Mg}$-ATP. Recordings were made using a MultiClamp 700B amplifier (Axon Instruments), sampled using Digidata 1440A and analyzed offline with pClamp 10.3 software (Axon Instruments). Series resistance was monitored during the recording, and the values were generally $<10 \mathrm{M} \Omega$ and were not compensated. The liquid junction potential was $+12.5 \mathrm{mV}$ and was corrected after the experiment. Data were excluded if the series resistance increased dramatically during the experiment or without overshoot for action potential. Currents were amplified, filtered at $1 \mathrm{kHz}$ and digitized at $20 \mathrm{kHz}$. Frequency and peak amplitude were measured using the Mini Analysis program (Synaptosoft Inc.). A current clamp was engaged to test neural firing frequency and resting membrane potential (RM) at baseline and after bath perfusion of apoA-IV $[0.1 \mu \mathrm{g} / \mathrm{ml}(2.18 \mathrm{nM}), 6$-min bath perfusion]. In some experiments, the aCSF solution also contained $1 \mu \mathrm{M}$ tetrodotoxin (TTX) [16] and a cocktail of fast synaptic inhibitors, namely bicuculline (50 $\mu \mathrm{M}$; a GABA receptor antagonist) [17], AP-5 (30 $\mu \mathrm{M}$; an NMDA receptor antagonist) [18] and CNQX (30 $\mu$; an AMPA receptor antagonist) [18] to block the majority of presynaptic inputs; in some experiments, AP-5 $(30 \mu \mathrm{M})$ and CNQX $(30 \mu \mathrm{M})$ were included in the aCSF solution to block glutamatergic inputs; in some experiments, bicuculline $(50 \mu \mathrm{M})$ was included in the aCSF solution to block GABAergic inputs. For the miniature excitatory postsynaptic current (mEPSC) recordings, the internal recording solution contained (in $\mathrm{mM}$ ): $125 \mathrm{CsCH}_{3} \mathrm{SO}_{3} ; 10 \mathrm{CsCl} ; 5 \mathrm{NaCl}$; $2 \mathrm{MgCl}_{2} ; 1$ EGTA; 10 HEPES; 5 (Mg)ATP, and $0.3(\mathrm{Na}) \mathrm{GTP}(\mathrm{pH}$ 7.3 with $\mathrm{NaOH}$ ). mEPSC in AgRP/NPY neurons was measured in the voltage clamp mode with a holding potential of $-60 \mathrm{mV}$ in the presence of $1 \mu \mathrm{M}$ TTX and $50 \mu \mathrm{M}$ bicuculline. The concentration of apoA-IV was chosen based on preliminary studies showing that 0.1 $\mu \mathrm{g} / \mathrm{ml}[2.18 \mathrm{nM}]$ apoA-IV produced consistent and reversible hyperpolarization in AgRP/NPY neurons. The values for RM, firing frequency and $\mathrm{mEPSC}$ were averaged within 2-min bin at the baseline or after apoA-IV perfusion. The RM values were calculated by Clampfit 10.3 using the 'analysis $\rightarrow$ statistic' function of the software. A neuron was considered depolarized or hyperpolarized if a change in membrane potential was at least $2 \mathrm{mV}$ in amplitude, and this response was observed after apoA-IV application and stayed stable for at least $4 \mathrm{~min}$ during the application. After recording each neuron, a lucifer yellow dye was injected into the recorded neuron via the pipette. Slices were fixed with $4 \%$ formalin in PBS at $4^{\circ} \mathrm{C}$ overnight and then subjected to post hoc identification of the anatomical location of the recorded neurons within the ARH.

\section{C-fos Immunoreactivity}

Male NPY-GFP mice ( 8 weeks of age) were anesthetized with inhaled isoflurane. As previously described [19, 20], mice were mounted onto the stereotaxic frame, on which stainless steel cannulae (Plastics One) were inserted into the lateral ventricles $(0.34$ $\mathrm{mm}$ caudal and $1 \mathrm{~mm}$ lateral from bregma; depth, $2.3 \mathrm{~mm}$ ). Intracerebroventricular (i.c.v.) cannulation was confirmed by demonstration of increased drinking and grooming behavior within $5 \mathrm{~min}$ after administration of angiotensin II ( $10 \mathrm{ng}$, in the morning of 3-4 days after surgeries); those mice that did not drink or groom within 5 min after angiotensin II injection were excluded from the following studies. Seven days after i.c.v. cannulations, mice were either fed ad libitum or fasted overnight and then received i.c.v. injections of apoA-IV $(1.5 \mu \mathrm{g}$ in $1 \mu \mathrm{l}$ saline) or saline $(1 \mu \mathrm{l})$. One hour after the i.c.v. injections, the mice were deeply anesthetized with inhaled isofluorane and perfused with $10 \%$ formalin. As negative controls, some male NPY-GFP mice (at 8 weeks of age) were perfused in the early morning in the fed condition. The fixed brains were collected and cut into $25-\mu \mathrm{m}$ coronal sections. These brain sections were subjected to dual immunofluorescence staining for GFP and c-fos. Briefly, the brain sections were incubated in the primary rabbit anti-c-fos antibody (1:20,000, No. PC38; Millipore) overnight, followed by donkey anti-rabbit AlexaFluor594 (1:500; Invitrogen) for $1.5 \mathrm{~h}$. Then, the sections were incubated in primary chicken anti-GFP antibody (1:5,000; Aves Labs Inc.) overnight followed by the goat anti-chicken AlexaFluor488 (1:250; Invitrogen) for $1.5 \mathrm{~h}$. Slides were coverslipped and analyzed using a Leica DM5500 fluorescence microscope with OptiGrid structured illumination configuration. The numbers of c-fos-positive GFP (AgRP/NPY) neurons in the ARH were counted by blinded investigators. For each mouse, neurons were counted in 3-5 consecutive brain sections containing the $\mathrm{ARH}$, and the average was treated as the data value for that mouse. Six mice were included in each treatment group for statistical analyses.

\section{Feeding Study}

Male WT mice and their MC4R-null littermates (at 8 weeks of age) were anesthetized with inhaled isoflurane and received i.c.v. cannulation as described above. Seven days after i.c.v. cannulations, the mice were fasted overnight and then received i.c.v. injections of apoA-IV $(1.5 \mu \mathrm{g}$ in $1 \mu \mathrm{l}$ saline $)$ or saline $(1 \mu \mathrm{l})$. Food was provided in each cage $30 \mathrm{~min}$ after i.c.v. injections. The food intake of each mouse was monitored at $0.5,1$ and $2 \mathrm{~h}$ after food was provided. Each mouse received both apoA-IV and saline injections on different days with a 7-day interval in between. The order of injections was randomized in order to avoid 'sequence effects'. Given that MC4R-null mice showed significantly higher body weight than WT littermates at the time of the feeding study, we included another group of obese WT mice. Briefly, male WT (C57B16) mice were fed with a high-fat diet (60\% fat, No. D12492; Research Diets) for 12 weeks. These mice were then surgically implanted with i.c.v. cannula, and effects of i.c.v. apoA-IV or saline on food intake were assessed as described above. Note that the dose of apoA-IV was chosen based on previous studies [9] and our pilot trials which showed consistent anorexigenic effects. 
apoA-IV Immunohistochemistry

To examine the distribution of apoA-IV in mouse hypothalamus, C57Bl6 mice were anesthetized with inhaled isoflurane and perfused with $10 \%$ formalin. Brains were collected and cut into $25-\mu \mathrm{m}$ coronal sections. These brain sections were subjected to apoA-IV immunohistochemistry. Briefly, brain sections were incubated with goat polyclonal anti-apoA-IV antibody $(1: 4,000)[21]$ at room temperature overnight, followed by biotinylated donkey anti-goat secondary antibody (1:1,000; Vector) for $2 \mathrm{~h}$. Sections were then incubated in the avidin-biotin complex (1:500, ABC; Vector Elite Kit) and incubated in $0.04 \% 3,3^{\prime}$-diaminobenzidine and $0.01 \%$ hydrogen peroxide. After dehydration through graded ethanol, the slides were immersed in xylene and coverslipped. Images were analyzed using a brightfield Leica microscope.

To examine the co-localization of apoA-IV and AgRP/NPY neurons, NPY-GFP mice were anesthetized with inhaled isoflurane and perfused with $10 \%$ formalin. Brains were collected and cut into $25-\mu \mathrm{m}$ coronal sections. These brain sections were incubated at room temperature in primary goat anti-apoA-IV antibody $(1: 4,000)$ overnight, followed by the secondary donkey anti-goat AlexaFluor594 (1:500) for $1.5 \mathrm{~h}$. Then, the sections were incubated in the primary chicken anti-GFP antibody $(1: 5,000)$ overnight, followed by secondary goat anti-chicken AlexaFluor488 (1:500; Invitrogen) for $1.5 \mathrm{~h}$. Slides were cover-slipped, and fluorescence images were analyzed using a confocal fluorescence microscope.

\section{Western Blot Assay}

C57Bl6 mice (at 8 weeks of age) were fasted overnight or fed ad libitum. Mice were then sacrificed in the early morning, and hypothalami were quickly isolated. Samples were lysed in lysis buffer (50 mM Tris-HCl, pH 8.0, $50 \mathrm{~mm} \mathrm{KCl,} 20 \mathrm{mM} \mathrm{NaF}, 1 \mathrm{mM} \mathrm{Na}_{3} \mathrm{VO}_{4}$, $10 \mathrm{~mm}$ sodium pyrophosphate, $5 \mathrm{~mm}$ EDTA and $0.5 \%$ Nonidet P-40) supplemented with protease inhibitors (1 mm phenylmethylsulfonyl fluoride and $20 \mu \mathrm{g} / \mathrm{ml}$ each of leupeptin, aprotinin and pepstatin). Lysates were cleared by centrifugation at $18,000 \mathrm{~g}$ for $10 \mathrm{~min}$ and used for Western blotting. Briefly, protein samples were loaded onto SDS-polyacrylamide gels and transferred to a nitrocellulose membrane. To detect apoA-IV protein, the blots were probed with goat anti-apoA-IV antibody (1:500) [21] overnight at $4{ }^{\circ} \mathrm{C}$, followed by donkey anti-goat-HRP antibody $(1: 15,000,1 \mathrm{~h}$ at room temperature; Santa Cruz, No. sc-2020). GAPDH was detected using a mouse monoclonal anti-GAPDH-

Fig. 1. Effects of apoA-IV on neural activities of AgRP/NPY neurons. a Electrophysiological recordings from identified AgRP/ NPY neurons in the ARH. Upper panels: microscopic images showing TOMATO (left), lucifer yellow (middle, injected through the pipette) and bright field image (right) of an AgRP/NPY neuron in the ARH-containing hypothalamic slice from an AgRP-IRESCre/Rosa26-tdTOMATO mouse. Lower panels: microscopic images showing TOMATO (left), lucifer yellow (middle) and merge image (right). The arrow points to the recorded neuron. $3 \mathrm{~V}=3 \mathrm{rd}$ ventricle. b Representative electrophysiological traces under the current clamp mode in AgRP/NPY neurons treated with $0.1 \mu \mathrm{g} / \mathrm{ml}$ apoA-IV perfusion. Lower panels are amplified traces at the baseline or after apoA-IV perfusion. c, $\mathbf{d}$ RM and firing frequency in fed or fasted AgRP/NPY neurons at baseline or after treatment of
HRP antibody (1:50,000, overnight at $4^{\circ}$ C; Sigma, No. G9295). Blots were developed with the SuperSignal West Pico Chemiluminescent Substrate (Pierce), and the reacted membranes were exposed to X-ray films. Scanned images were subjected to densitometry analyses using the ImageJ software. The ratios of apoA-IV/ GAPDH from each sample were calculated as relative apoA-IV protein levels. Four mice were included in each treatment group for statistical analyses.

\section{Statistics}

The data are presented as mean \pm SEM. Statistical analyses were performed using GraphPad Prism. Depending on the design of experiments, data were compared by $t$ tests or by one-way or twoway ANOVA followed by post hoc Sidak's tests (as specified in figure legends). $\mathrm{p}<0.05$ was considered to be statistically significant.

\section{Results}

\section{apoA-IV Inhibits AgRP/NPY Neurons in vitro}

Evidence suggests that central administration of apoAIV inhibits food intake via acting through the central melanocortin pathways [9], but the effects of apoA-IV on melanocortin neurons, e.g. AgRP/NPY neurons in the $\mathrm{ARH}$, have not been directly tested. To address the effects of apoA-IV on AgRP/NPY neurons at the cellular level, we performed whole-cell patch clamp electrophysiological recordings in identified AgRP/NPY neurons using AgRP-IRES-Cre/Rosa26-tdTOMATO mice (fig. 1a). First, in the aCSF containing $11.1 \mathrm{mM}$ glucose, we recorded 11 AgRP/NPY neurons from mice in the fed condition. Remarkably, apoA-IV $(0.1 \mu \mathrm{g} / \mathrm{ml}, 4$ - to 6-min bath perfusion) hyperpolarized the RM in 9 out of 11 fed AgRP/ NPY neurons (before apoA-IV: RM $=-41.37 \pm 1.30 \mathrm{mV}$; after apoA-IV: $\mathrm{RM}=-45.51 \pm 1.73 \mathrm{mV}$; fig. $1 \mathrm{~b}, \mathrm{c}$ ). In addition, all these 11 neurons responded to apoA-IV with

apoA-IV in aCSF containing 11.1 or $4 \mathrm{~mm}$ glucose. Data are presented as mean \pm SEM $(\mathrm{n}=11-16$ in $11.1 \mathrm{mM}$ glucose; $\mathrm{n}=5-6$ in $4 \mathrm{~mm}$ glucose). ${ }^{*} \mathrm{p}<0.01,{ }^{* * *} \mathrm{p}<0.001$ in two-way ANOVA analysis repeat measurements followed by post hoc Sidak's test. e, f Representative electrophysiological traces under the current clamp mode in AgRP/NPY neurons treated with $0.1 \mu \mathrm{g} / \mathrm{ml}$ apoAIV perfusion in the presence of TTX, bicuculline, AP-5 and CNQX, or the presence of AP-5 and CNQX. $\mathbf{f}$ Lower panels are amplified traces at baseline or after apoA-IV perfusion. $\mathbf{g}, \mathbf{h}$ RM and firing frequency in AgRP/NPY neurons at baseline or after treatment of apoA-IV in the presence of various inhibitors. Data are presented as mean \pm SEM $(\mathrm{n}=11-16)$. ${ }^{* * *} \mathrm{p}<0.001$ in two-way ANOVA analysis repeat measurements followed by post hoc Sidak's multiple comparison tests.

(For figure see next page.) 
robust decreases in the firing rate (before apoA-IV: 5.56 $\pm 0.68 \mathrm{~Hz}$; after apoA-IV: $2.90 \pm 0.54 \mathrm{~Hz}$; fig. $1 \mathrm{~d})$. We then examined the effects of apoA-IV on 16 AgRP/NPY neurons from mice that had been fasted overnight. apoA-IV treatment hyperpolarized 14 out of 16 fasted AgRP/NPY neurons tested (baseline: $\mathrm{RM}=-41.06 \pm 0.78 \mathrm{mV}$; after apoA-IV: $\mathrm{RM}=-46.86 \pm 0.92 \mathrm{mV}$; fig. $1 \mathrm{c}$ ), which were associated with significant decreases in the firing rate (baseline: $7.51 \pm 0.54 \mathrm{~Hz}$; after apoA-IV: $3.58 \pm 0.46 \mathrm{~Hz}$; fig. 1d). Notably, we also noted that the baseline firing rate (before apoA-IV treatment) in fasted AgRP/NPY neurons was significantly higher than that of fed AgRP/ NPY neurons, although no significant differences in baseline RM were observed between the fasted and fed
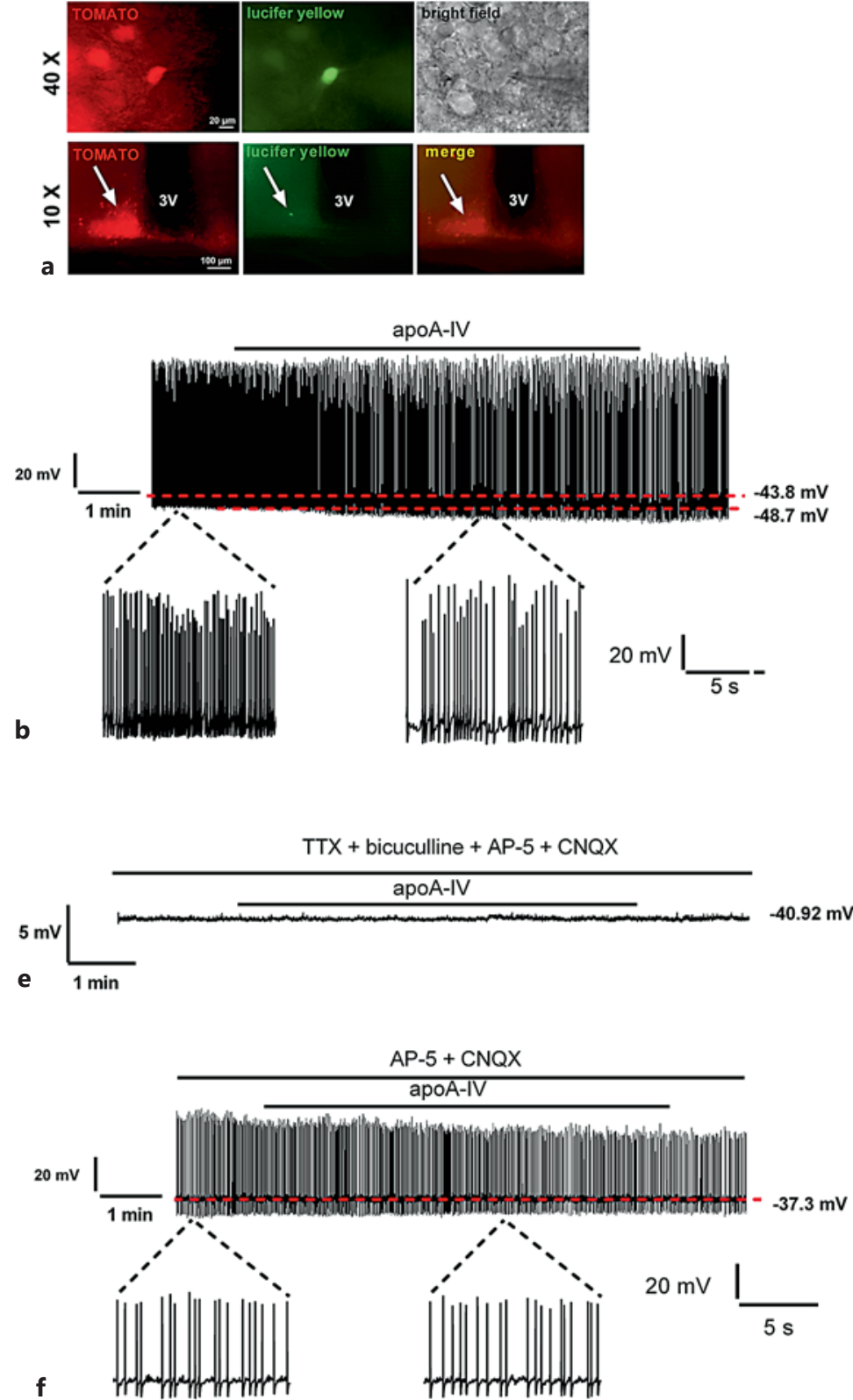

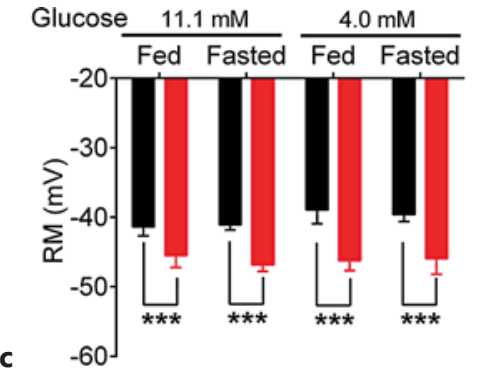

Baseline

apoA-IV

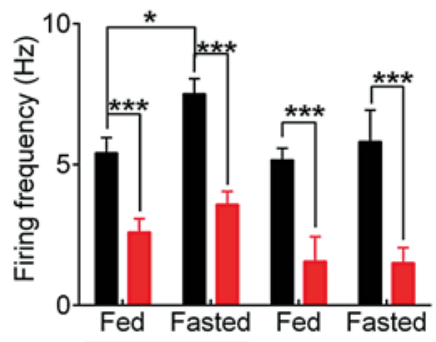

Baseline

ApoA-IV

d
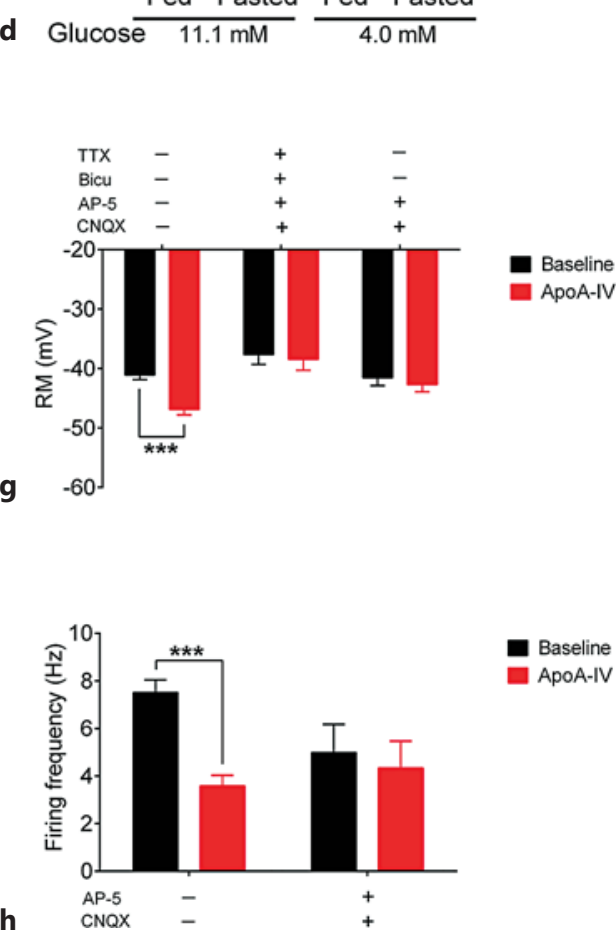

1

Yan/He/Xu/Shu/Wang/Yang/Saito/Xu/ Hinton Jr./Yan/Yu/Wu/Tso/Tong/Xu 
AgRP/NPY neurons (fig. 1c, d). These results are consistent with previous observations that AgRP/NPY neurons in brain slices prepared from fasted mice have an increased firing activity compared to those prepared from fed mice $[18,22]$. We further performed similar recordings in aCSF containing $4 \mathrm{mM}$ glucose and observed similar inhibitory effects of apoA-IV on AgRP/NPY neurons from fed or fasted mice.

To determine if the effects of apoA-IV are mediated via presynaptic or postsynaptic mechanisms, we examined effects of apoA-IV on AgRP/NPY neurons in the presence of TTX and a cocktail of fast synaptic inhibitors (bicuculline, AP-5 and CNQX). Remarkably, in this condition, the apoA-IV-induced hyperpolarization was blocked in 14 out of $15 \mathrm{AgRP} / \mathrm{NPY}$ neurons recorded (baseline: $\mathrm{RM}=-37.64 \pm 1.67 \mathrm{mV}$; after apoA-IV: $\mathrm{RM}=$ $-38.44 \pm 1.86 \mathrm{mV}$; fig. 1e, g; table 1). Thus, these results suggest that apoA-IV inhibits AgRP/NPY neurons likely via presynaptic mechanisms.

Since AgRP/NPY neurons are known to receive excitatory presynaptic inputs from glutamatergic neurons [23], we then examined the effects of apoA-IV on AgRP/ NPY neurons that have been preincubated with glutamate receptor inhibitors (AP-5 and CNQX). In 9 out of 11 neurons recorded under this condition, apoA-IV treatment failed to significantly hyperpolarize the RM (baseline: $\mathrm{RM}=-41.54 \pm 1.34 \mathrm{mV}$; after apoA-IV: $\mathrm{RM}=$ $-42.70 \pm 1.22 \mathrm{mV}$; fig. $1 \mathrm{f}$, g; table 1$)$ or the firing frequency (baseline: $\mathrm{RM}=4.99 \pm 1.18 \mathrm{mV}$; after apoA-IV: $\mathrm{RM}=$ $4.33 \pm 1.34 \mathrm{mV}$; fig. 1f, h). Thus, these results further indicate that the effects of apoA-IV on AgRP/NPY neurons are mediated largely through regulation of glutamatergic inputs.
It is known that glutamatergic inputs to AgRP/NPY neurons lead to excitatory postsynaptic current (EPSC) in these neurons [18]. Here, we tested if apoA-IV regulates mEPSC in AgRP/NPY neurons. We found that apoA-IV significantly decreased the frequency of mEPSC (baseline: $2.89 \pm 0.31 \mathrm{~Hz}$; after apoA-IV: $1.42 \pm 0.31 \mathrm{~Hz}$; fig. $2 \mathrm{a}$, b), while the amplitude of mEPSC was not altered by apoA-IV (baseline: $25.56 \pm 0.74 \mathrm{pA}$; after apoA-IV: 25.84 $\pm 0.75 \mathrm{pA}$; fig. 2a, c). Together, these electrophysiological studies indicate that apoA-IV decreased the firing of

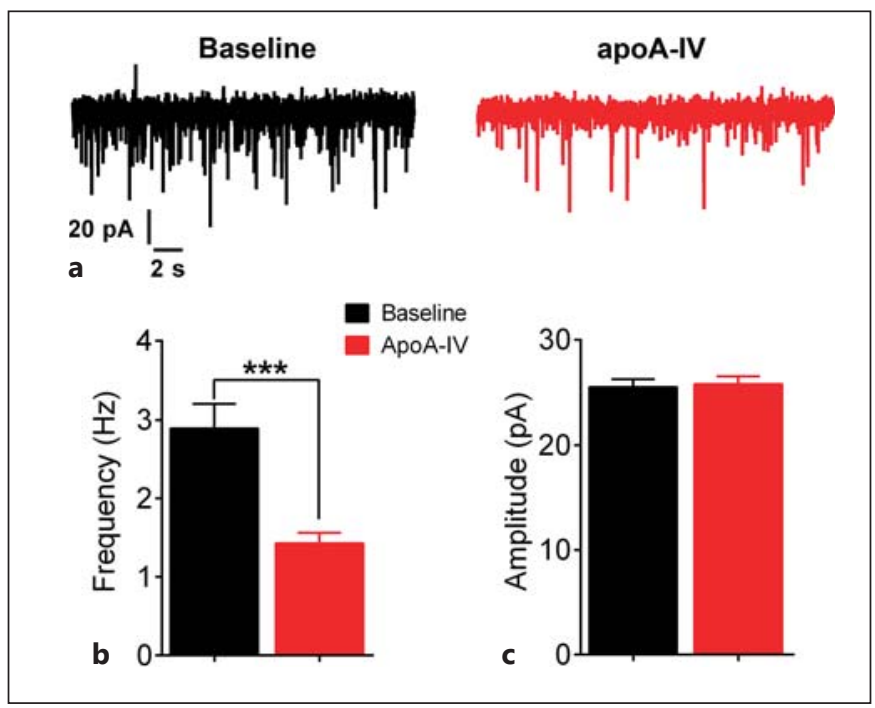

Fig. 2. Effects of apoA-IV on mEPSC in AgRP/NPY neurons. a Representative mEPSC at baseline or after $0.1 \mu \mathrm{g} / \mathrm{ml}$ apoA-IV treatment in AgRP/NPY neurons. b, c Frequency and amplitude of mEPSC in AgRP/NPY neurons. Data are presented as mean \pm $\operatorname{SEM}(\mathrm{n}=17){ }^{* * *} \mathrm{p}<0.001$ in paired t tests.

Table 1. Number of neurons that responded to apoA-IV

\begin{tabular}{llllll}
\hline Neuron & Pretreatment & \multicolumn{2}{l}{$\mathrm{n}(\%$ of total $)$} & & \\
\cline { 3 - 5 } & & total & depolarize & hyperpolarize & no response \\
\hline \multirow{2}{*}{ AgRP } & None & 16 & $0(0)$ & $14(87.5)$ & $2(12.5)$ \\
& TTX + Bicu + AP-5 + CNQX & 15 & $1(6.67)$ & $1(6.67)^{\mathrm{a}}$ & $13(86.67)^{\mathrm{a}}$ \\
& AP-5 + CNQX & 11 & $0(0)$ & $2(18.18)^{\mathrm{a}}$ & $9(81.82)^{\mathrm{a}}$ \\
\hline POMC & None & 12 & $10(83.33)$ & $2(16.67)$ & $0(0)$ \\
& Bicu & 17 & $2(11.76)^{\mathrm{b}}$ & $2(11.76)$ & $13(76.47)^{\mathrm{b}}$ \\
\hline
\end{tabular}

Depolarization was defined as $>2 \mathrm{mV}$ elevations in RM within $3 \mathrm{~min}$ after apoA-IV application; hyperpolarization was defined as $>2$ $\mathrm{mV}$ reductions in $\mathrm{RM}$ within 3 min after apoA-IV application; other neurons were defined as no response. ${ }^{\mathrm{a}} \mathrm{p}<0.05 \mathrm{vs} . \mathrm{AgRP}$ neurons receiving no pretreatment $\left(\chi^{2}\right.$ test $) ;{ }^{b} \mathrm{p}<0.05$ vs. POMC neurons receiving no pretreatment $\left(\chi^{2}\right.$ test). 


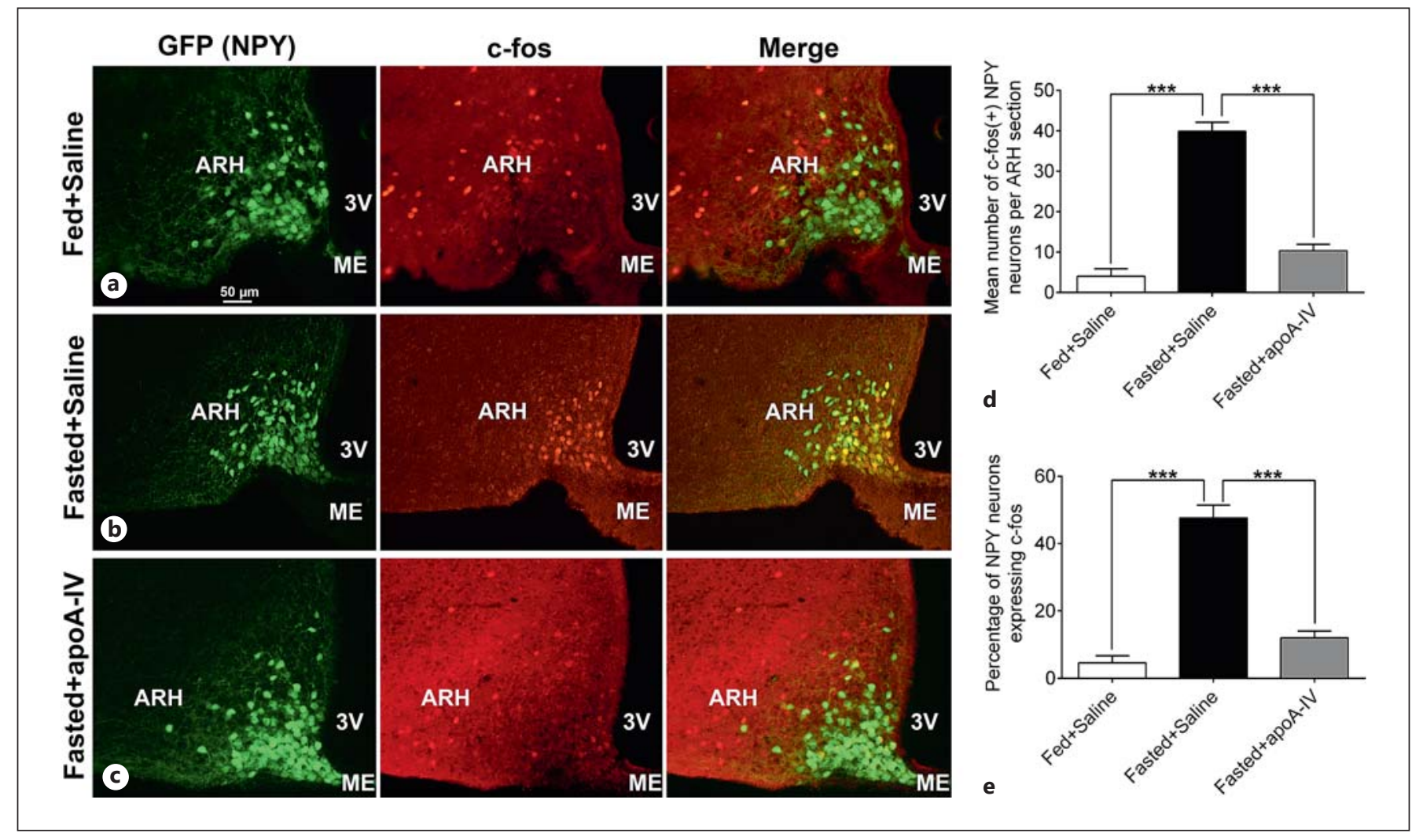

Fig. 3. Effects of i.c.v. apoA-IV on fast-induced c-fos in AgRP/NPY neurons. Representative c-fos (red) and GFP (green) immunofluorescence staining in the ARH of NPY-GFP mice that were fed and received an i.c.v. injection of saline (a), fasted overnight and received an i.c.v. injection of saline (b), or fasted overnight and re- ceived an i.c.v. injection of apoA-IV $(1.5 \mu \mathrm{g}, 1 \mathrm{~h}$; c). d, e Quantifications of c-fos-positive GFP neurons. $\mathbf{d}$ The number of neurons per ARH section. e Percent of NPY neurons. Data are presented as mean \pm SEM ( $n=6$ in each group). ${ }^{*} \mathrm{p}<0.05$ in one-way ANOVA analysis followed by post hoc Sidak's multiple comparison tests.
AgRP/NPY neurons, which were associated with hyperpolarized RM and decreased mEPSC frequency.

\section{apoA-IV Inhibits Fast-Induced c-fos in ARH AgRP/ \\ NPY Neurons}

Since the electrophysiological data provided in vitro evidence that apoA-IV inhibits AgRP/NPY neurons, we then tested if central administration of apoA-IV also inhibits AgRP/NPY neurons in vivo, using c-fos immunoreactivity as a marker for neuronal activation. To this end, we used NPY-GFP mice, in which all GFP-labelled neurons in the ARH are known to be AgRP/NPY neurons [13]. When mice were fed and received an i.c.v. injection of saline, minimal c-fos immunoreactivity was detected in AgRP/NPY neurons (fig. 3a, d, e). On the other hand, after an overnight fast and an i.c.v. injection of saline, we detected abundant c-fos expression in ARH AgRP/NPY neurons (fig. 3b, d, e). Importantly, we showed that i.c.v. injections of apoA-IV $(1.5 \mu \mathrm{g})$ in fasted mice significantly reduced c-fos immunoreactivity in AgRP/NPY neurons (fig. 3c-e). Thus, these results are consistent with in vitro electrophysiological recordings and indicate that central apoA-IV can inhibit AgRP/NPY neurons in vivo.

\section{apoA-IV Activates ARH POMC Neurons in vitro}

It is well established that ARH AgRP/NPY neurons directly synapse on the adjacent POMC neurons and inhibit POMC neurons [10, 24]. Given the inhibitory effects of apoA-IV on ARH AgRP/NPY neurons, we speculate that apoA-IV can activate ARH POMC neurons. To test this, we performed whole-cell patch clamp electrophysiological recordings in identified POMC neurons using POMC-CreER/Rosa26-tdTOMATO mice (fig. 4a). We showed that apoA-IV $(0.1 \mu \mathrm{g} / \mathrm{ml}$, 4- to 6-min bath perfusion) depolarized 10 out of 12 POMC neurons tested (baseline: $\mathrm{RM}=-47.05 \pm 1.05 \mathrm{mV}$; after apoA-IV: $\mathrm{RM}=$ 


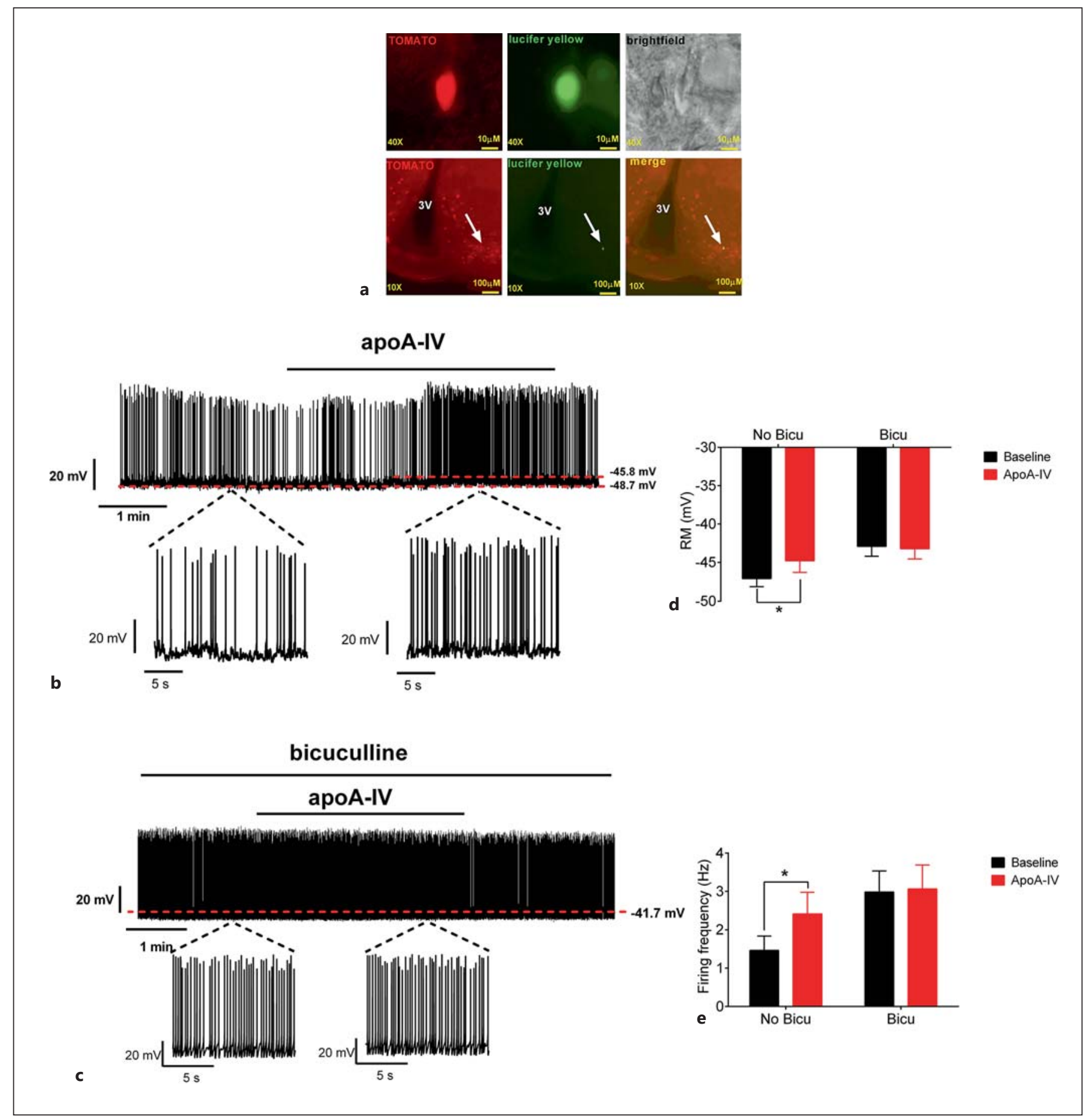

Fig. 4. Effects of apoA-IV on neural activities of POMC neurons. a Electrophysiological recordings from identified POMC neurons in the ARH. Upper panels: Microscopic images showing TOMATO (left), lucifer yellow (middle, injected through the pipette) and bright field image (right) of a POMC neuron in the ARH-containing hypothalamic slice from a POMC-CreER/Rosa26-tdTOMATO mouse (with tamoxifen induction). Scale bars $=10 \mu \mathrm{m}$. Lower panels: Microscopic images showing TOMATO (left), lucifer yellow (middle) and merge image (right). The arrow points to the recorded neuron. Scale bars $=100 \mu \mathrm{m} .3 \mathrm{~V}=3 \mathrm{rd}$ ventricle. b, c Representative electrophysiological traces under the current clamp mode in POMC neurons treated with $0.1 \mu \mathrm{g} / \mathrm{ml}$ apoA-IV perfusion in the absence or the presence of bicuculline. Lower panels are amplified traces at baseline or after apoA-IV perfusion. d, e RM and firing frequency in POMC neurons. Data are presented as mean \pm SEM $(n=12-17) .{ }^{*} \mathrm{p}<0.05$ in two-way ANOVA analyses repeat measurements followed by post hoc Sidak's multiple comparison tests. 
Fig. 5. Effects of i.c.v. apoA-IV on food intake. a Fast-induced refeeding response in WT lean mice receiving i.c.v. injections of saline or apoA-IV $(1.5 \mu \mathrm{g}, 30 \mathrm{~min}$ prior to food provision). b Fast-induced refeeding response in MC4R-null mice receiving i.c.v. injections of saline or apoA-IV (1.5 $\mu \mathrm{g}, 30 \mathrm{~min}$ prior to food provision). c Fastinduced refeeding response in WT DIO mice receiving i.c.v. injections of saline or apoA-IV $(1.5 \mu \mathrm{g}, 30 \mathrm{~min}$ prior to food provision). $\mathbf{d}$ Body weight of mice at the time of i.c.v. experiments. Data are presented as mean \pm SEM ( $n=4-6$ in each group). n.s. $=$ No significance. ${ }^{*} \mathrm{p}<0.05,{ }^{* * *} \mathrm{p}<$ 0.001 in $t$ test at each time point $(\mathbf{a}-\mathbf{c})$ or in one-way ANOVA followed by post hoc Sidak's multiple comparison tests (d).

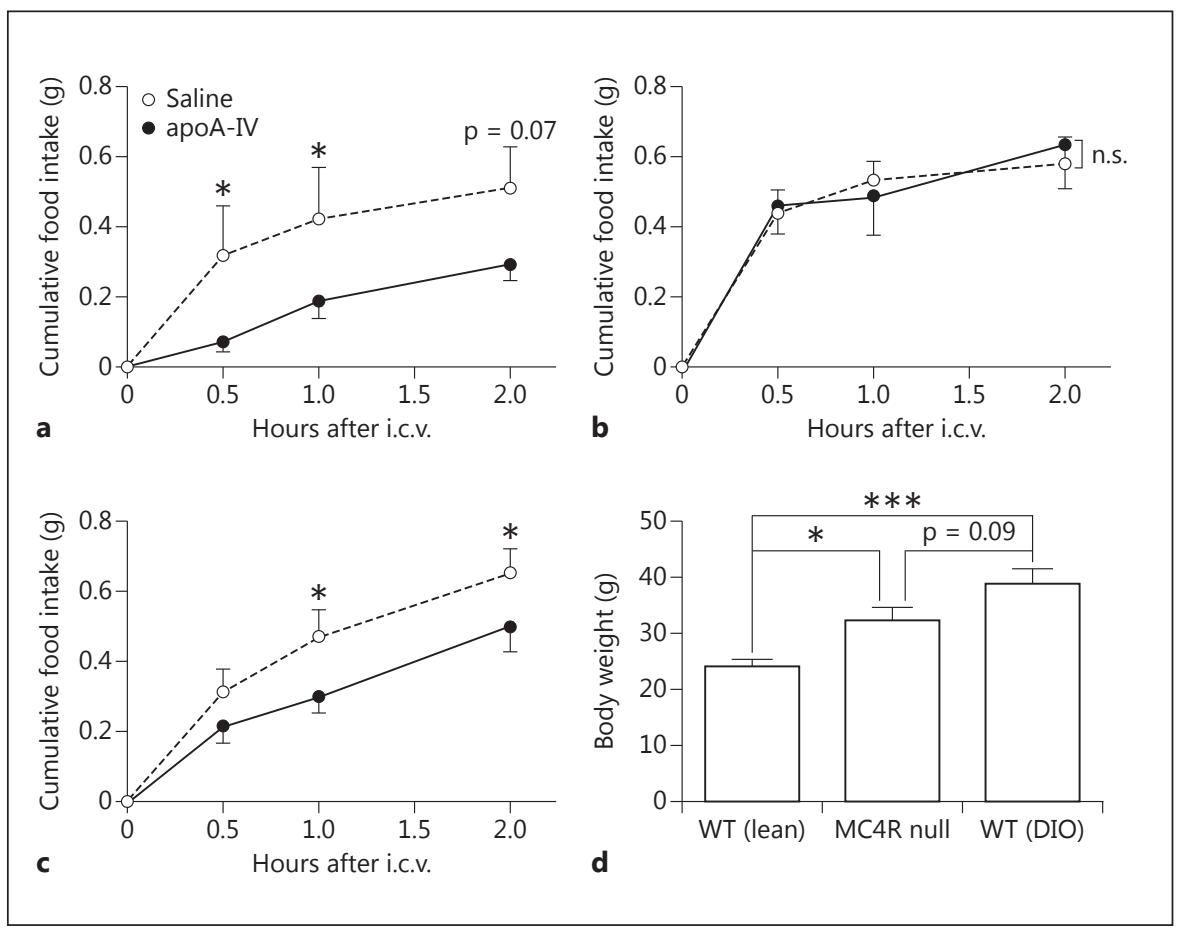

$-44.80 \pm 1.52 \mathrm{mV}$; fig. $4 \mathrm{~b}$, d; table 1), which were associated with significant increases in the firing rate (baseline: $1.46 \pm 0.37 \mathrm{~Hz}$; after apoA-IV: $2.42 \pm 0.56 \mathrm{~Hz}$; fig. 4b, e).

Since POMC neurons are known to receive GABAergic inputs from AgRP/NPY neurons [10, 24], we then examined the effects of apoA-IV on POMC neurons that had been preincubated with the GABA receptor antagonist (bicuculline). In 15 out of 17 neurons recorded under this condition, apoA-IV treatment failed to significantly depolarize the RM (baseline: $\mathrm{RM}=-42.91 \pm 1.28 \mathrm{mV}$; after apoA-IV: $\mathrm{RM}=-43.22 \pm 1.32 \mathrm{mV}$; fig. $4 \mathrm{c}$, d; table 1 ) or the firing frequency (baseline: $\mathrm{RM}=2.99 \pm 0.55 \mathrm{mV}$; after apoA-IV: $\mathrm{RM}=3.06 \pm 0.63 \mathrm{mV}$; fig. $4 \mathrm{c}, \mathrm{e})$. Thus, these results further indicate that the effects of apoA-IV on POMC neurons are mediated largely through regulation of GABAergic inputs.

\section{Deletion of MC4Rs Blocks the Anorexigenic Effects of Central apo $A-I V$}

We then tested if the anorexigenic effects of central apoA-IV require intact MC4Rs. To this end, effects of i.c.v. apoA-IV on fast-induced refeeding were compared in obese MC4R-null mice and their lean WT littermates. Consistent with earlier reports [3,9], we showed that i.c.v. apoA-IV $(1.5 \mu \mathrm{g})$ in lean WT mice significantly suppressed food intake at 0.5 and $1 \mathrm{~h}$ after refeeding, and showed a trend of suppression at $2 \mathrm{~h}$ time point (fig. 5a). Importantly, i.c.v. apoA-IV failed to significantly reduce food intake in MC4R-null mice at all time points in the same fast-induced refeeding paradigm (fig. 5b).

Notably, at the time of these feeding experiments, MC4R-null mice already developed obesity, as demonstrated by significant increases in body weight compared to their WT littermates (fig. 5d). To exclude the possibility that the loss of apoA-IV effects in MC4R-null mice may be due to obesity per se, we tested apoA-IV effects in a separate cohort of WT mice that developed diet-induced obesity (DIO) after chronic high-fat diet feeding. Despite the fact that these DIO mice had comparable body weight to that of MC4R-null mice (fig. 5d), i.c.v. apoA-IV still significantly suppressed food intake in these DIO mice at 1 and $2 \mathrm{~h}$ after refeeding (fig. $5 \mathrm{c}$ ). Together, these results indicate that central administration of apoAIV is efficacious in suppressing food intake in both lean and obese mice, and that these anorexigenic effects of apoA-IV require intact MC4Rs.

\section{Endogenous apoA-IV in the Hypothalamus Is Regulated by Feeding}

Since circulating apoA-IV cannot pass the blood-brain barrier [21], an important question is whether neurons in the brain produce endogenous apoA-IV. To address this 


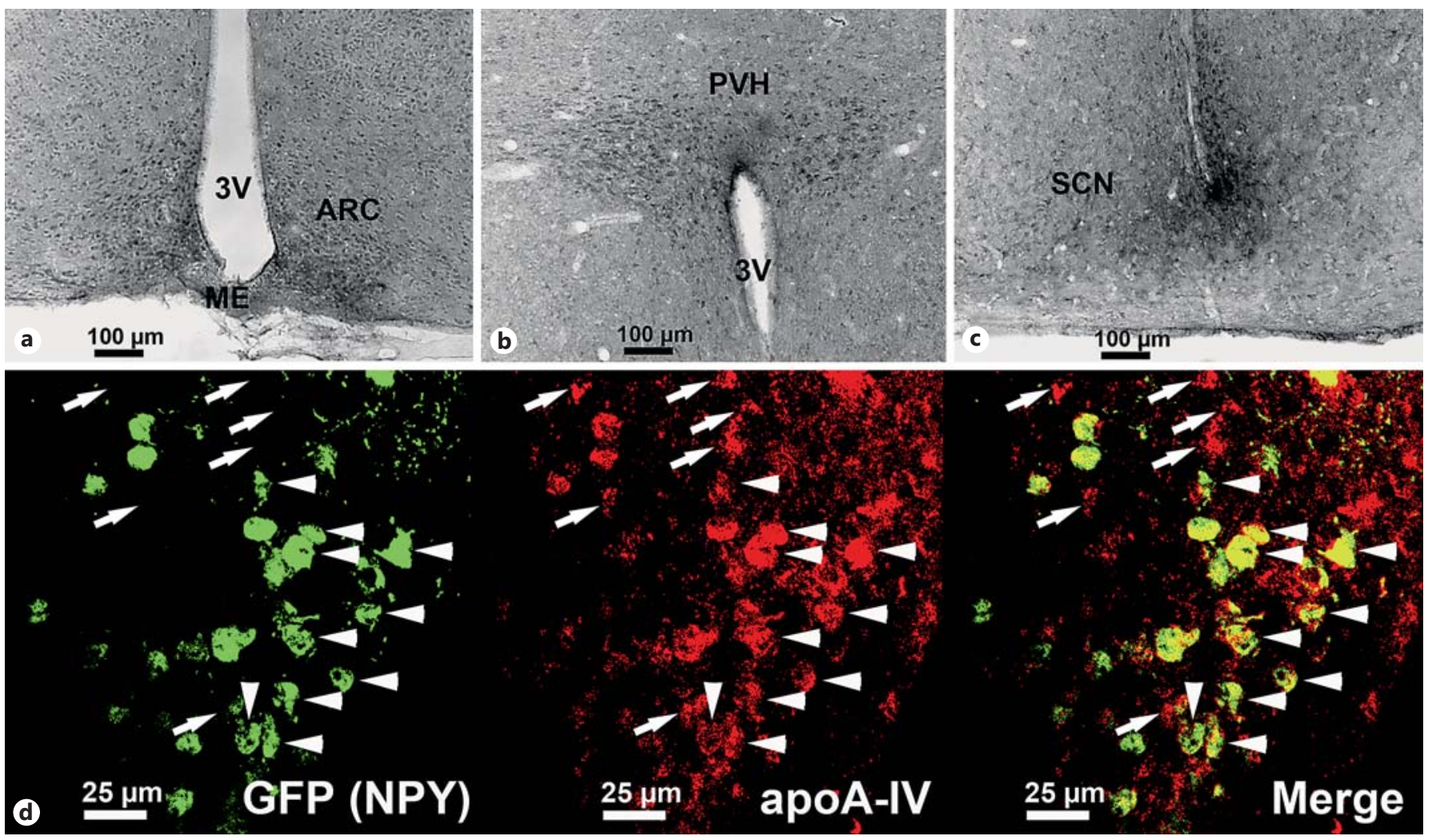

Fig. 6. Expression of the apoA-IV protein in mouse hypothalamus. a-c Representative apoA-IV immunohistochemistry staining in mouse hypothalamus. $3 \mathrm{~V}=3 \mathrm{rd}$ ventricle; $\mathrm{ME}=$ median eminence. d Representative confocal immunofluorescence staining for GFP (green), apoA-IV (red) and merged image (yellow) in the ARH of NPY-GFP mice. Scale bars $=25 \mu \mathrm{m}$. Arrowheads point to doublelabelled neurons; arrows point to apoA-IV-positive neurons that are not GFP labelled. question, we examined the expression of apoA-IV protein using immunohistochemistry. We found abundant apoA-IV immunoreactivity in the ARH, the paraventricular nucleus of the hypothalamus (PVH) and the suprachiasmatic nucleus (SCN; fig. 6a-c). We further examined the co-localization of apoA-IV and AgRP/NPY neurons in the ARH using dual immunofluorescence for apoA-IV and GFP in NPY-GFP mice. Remarkably, we found that the majority of AgRP/NPY neurons co-express apoA-IV (arrowheads in fig. 6d), while a small portion of apoA-IV in the ARH is also present in non-AgRP/ NPY neurons (arrows in fig. 6d), which might include POMC neurons.

Finally, we used Western blotting analyses to confirm the presence of endogenous apoA-IV protein in the mouse hypothalamus (fig. 7a). More importantly, we found that hypothalamic apoA-IV levels were significantly reduced by an overnight fast (fig. 7a, b), suggesting that the hypothalamic apoA-IV may play a physiologically relevant role in the regulation of feeding behavior.

apoA-IV Regulates Melanocortin

Neurons

\section{Discussion}

\section{apoA-IV Inhibits AgRP/NPY Neurons}

While it has long been suggested that apoA-IV acts centrally to suppress food intake [3], the actual neural populations that respond to apoA-IV and mediate its anorexigenic effects remain unknown. One major finding of our current study is that apoA-IV significantly suppressed firing in AgRP/NPY neurons, which was accompanied with membrane hyperpolarization. These electrophysiological observations were further supported by our in vivo evidence that i.c.v. apoA-IV nearly abolished activation of AgRP/NPY neurons (demonstrated by c-fos immunoreactivity) in fasted mice. Together, these results provide evidence that apoA-IV inhibits AgRP/NPY neurons.

Since no receptors for apoA-IV have been identified [2], the molecular mechanisms underlying apoA-IV actions are difficult to unravel. Nevertheless, our results suggested a potential cellular mechanism. We showed that the inhibitory effects of apoA-IV on AgRP/NPY neu- 


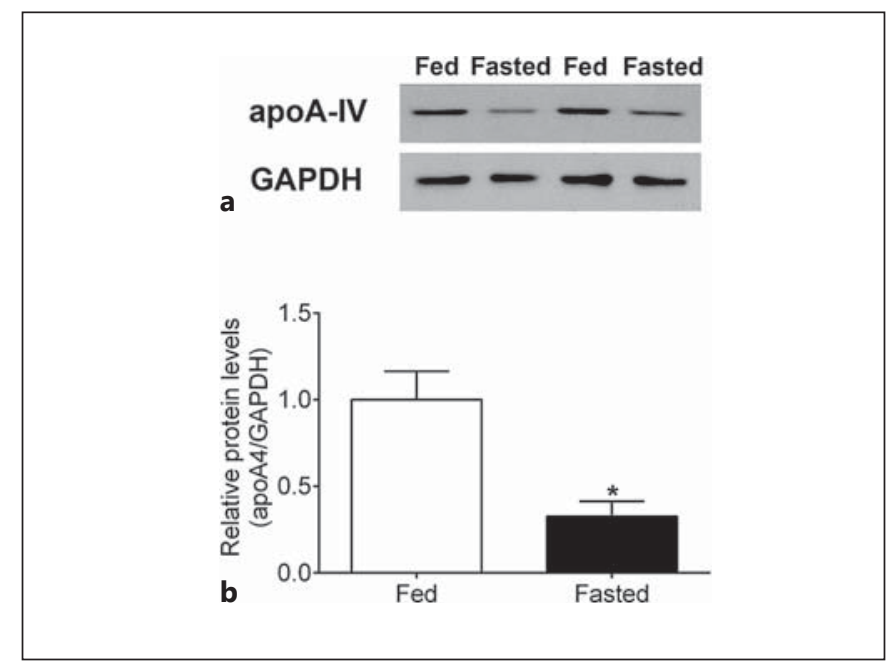

Fig. 7. Effects of food deprivation on hypothalamic apoA-IV protein levels. a Representative Western blotting for apoA-IV and GAPDH in the hypothalamus isolated from fed or fasted mice. b Quantification of relative apoA-IV protein levels in the hypothalamus isolated from fed or fasted mice. Data are presented as mean $\pm \operatorname{SEM}(\mathrm{n}=4$ in each condition $) .{ }^{*} \mathrm{p}<0.05$ in $\mathrm{t}$ test.

rons can be largely blocked by TTX and a cocktail of fast synaptic inhibitors. These results suggest that apoA-IV inhibits AgRP/NPY neurons predominantly through presynaptic mechanisms. Notably, it has recently been shown that AgRP/NPY neurons receive strong glutamatergic inputs from other hypothalamic regions [23], and genetic deletion of glutamatergic receptors in AgRP/NPY neurons decreases EPSC in these neurons [18]. Here, we showed that apoA-IV inhibited the frequency of mEPSC in AgRP/NPY neurons, while the amplitude of mEPSC was not affected. This pattern is in line with the notion that apoA-IV may act presynaptically to decrease release of excitatory neurotransmitters onto AgRP/NPY neurons, while postsynaptic effects of apoA-IV may be minor. Further supporting this possibility, we found that pretreatment of glutamatergic NMDA and AMPA receptor antagonists largely abolished the inhibitory effects of apoA-IV on both RM and the firing frequency of AgRP/ NPY neurons.

Given the inhibitory effects of apoA-IV on ARH AgRP/NPY neurons, our observations that apoA-IV also activates POMC neurons are conceivable because ARH POMC are known to receive GABAergic inputs from adjacent AgRP/NPY neurons [10, 24]. Consistently, we demonstrated that the activation of POMC neurons induced by apoA-IV was largely blocked by the GABA receptor antagonist. Collectively, our findings suggest a model where apoA-IV acts upon the presynaptic terminals to inhibit excitatory glutamatergic inputs onto AgRP/ NPY neurons and therefore inhibit these neurons, which indirectly disinhibits (activates) POMC neurons.

It is worth noting that while most of AgRP/NPY and POMC neurons failed to respond to apoA-IV in the presence of synaptic inhibitors (TTX, glutamate receptor antagonists and/or GABA receptor antagonist), a small portion of AgRP/NPY or POMC neurons were hyperpolarized or depolarized by apoA-IV, respectively, even in the presence of these inhibitors (table 1). These observations suggest that apoA-IV may act directly upon at least subsets of neurons, although these postsynaptic actions appear to be minor compared to the presynaptic effects of apoA-IV on these melanocortin neurons.

\section{The Central Melanocortin Pathway Mediates}

Anorexigenic Effects of apoA-IV

The inhibitory effects of apoA-IV on the firing of AgRP/NPY neurons presumably lead to decreased release of AgRP, which acts as an inverse agonist of MC4Rs to stimulate food intake [25]. In parallel, activated POMC neurons may release $\alpha$-melanocyte-stimulating hormone to activate MC4Rs [25]. It has been shown in rats that central administration of an MC4R antagonist (SHU9119) can block the effects of apoA-IV to suppress food intake [9]. Here, we provided genetic evidence that the anorexigenic effects of apoA-IV were abolished in MC4R-null mice. Given that the anorexigenic effects of apoA-IV were largely conserved in WT DIO mice, we believe that the lack of apoA-IV effects in MC4R-null mice was not due to obesity per se, but rather to the lack of MC4Rs. Together, these results support a possibility that apoA-IV inhibits AgRP/NPY neurons and activates POMC neurons, which in turn leads to increased MC4R activation to result in suppression of food intake.

Notably, another neurotransmitter released from AgRP/NPY neurons, NPY, also strongly stimulates food intake [26]. Although no evidence supports the involvement of NPY signals in apoA-IV-induced anorexia, this possibility cannot be fully ruled out.

\section{The Hypothalamus Synthesizes Endogenous apoA-IV}

We detected abundant apoA-IV in various hypothalamic regions, including the ARH, PVH and SCN. Consistently, endogenous apoA-IV has been detected in human cerebrospinal fluid [27] and in rat hypothalamus [21]. In particular, we found that many AgRP/NPY neurons in the ARH co-express apoA-IV, which suggests that apoA-IV may be released from these AgRP/NPY neurons 
and act in an autocrine or paracrine fashion. Notably, a portion of PVH neurons project and synapse on AgRP/ NPY neurons [23]. Thus, apoA-IV in PVH neurons may also signal AgRP/NPY neurons. Since circulating apoAIV does not cross the blood-brain barrier [21], the presence of apoA-IV in the hypothalamus provides an anatomical basis for a physiological role of this peptide in neurons. More importantly, we demonstrated that the protein levels of apoA-IV in the hypothalamus are dramatically reduced by an overnight fast. Given the inhibitory effects of apoA-IV on AgRP/NPY neural activity, the decreased hypothalamic apoA-IV levels might at least partly contribute to the fasting-induced activation of AgRP/NPY neurons [18, 22].

Notably, central administration of an apoA-IV-neutralizing antibody has been shown to significantly increase food intake in satiated rats (with high apoA-IV) [3], supporting a physiologically relevant role of brainderived apoA-IV in feeding control. In addition, genetic deletion of apoA-IV in mice leads to significantly enhanced fast-induced refeeding compared to WT mice [4], although these phenotypes may also be attributed to the loss of apoA-IV synthesis in the peripheral tissues. Nevertheless, the physiological functions of brain-derived apoA-IV in the regulation of feeding behavior warrant further investigations.
In summary, we provided the first evidence to support a novel concept that apoA-IV can rapidly regulate the firing of a neuron. In particular, we demonstrated that apoA-IV inhibits ARH AgRP/NPY neurons and activates ARH POMC neurons at least partly through presynaptic mechanisms. Further, our data identified the central melanocortin circuit as one site where central apoA-IV acts to suppress food intake. In addition, we demonstrated that multiple hypothalamic neural populations produce apoA-IV as a potential source of this anorexigenic peptide in the brain. Lastly, the potent anorexigenic effects of central apoA-IV, which largely persist in obese mice, indicate that hypothalamic apoA-IV is a rational target for development of anti-obesity therapy.

\section{Acknowledgements}

This work was supported bygrants from the NIH(R01DK093587 and R01DK101379 to Yong Xu; R01DK092605 to Qingchun Tong; R25GM56929 to Antentor Othrell Hinton Jr), and by the American Heart Association postdoctoral fellowship (Pingwen $\mathrm{Xu}$ ).

\section{Disclosure Statement}

The authors have no conflicts of interest to disclose.

\section{References}

1 Apfelbaum TF, Davidson NO, Glickman RM: Apolipoprotein A-IV synthesis in rat intestine: regulation by dietary triglyceride. Am J Physiol 1987;252:G662-G666.

- 2 Wang F, Kohan AB, Lo CM, Liu M, Howles P, Tso P: Apolipoprotein A-IV: a protein intimately involved in metabolism. J Lipid Res 2015;56:1403-1418.

3 Fujimoto K, Fukagawa K, Sakata T, Tso P: Suppression of food intake by apolipoprotein A-IV is mediated through the central nervous system in rats. J Clin Invest 1993;91:18301833.

4 Weinstock PH, Bisgaier CL, Hayek T, AaltoSetala K, Sehayek E, Wu L, Sheiffele P, Merkel M, Essenburg AD, Breslow JL: Decreased HDL cholesterol levels but normal lipid absorption, growth, and feeding behavior in apolipoprotein A-IV knockout mice. J Lipid Res 1997;38:1782-1794.

$5 \mathrm{Xu}$ Y, Elmquist JK, Fukuda M: Central nervous control of energy and glucose balance: focus on the central melanocortin system. Ann NY Acad Sci 2011;1243:1-14.
6 Lin S, Boey D, Herzog H: NPY and Y receptors: lessons from transgenic and knockout models. Neuropeptides 2004;38:189-200.

7 Cone RD: The central melanocortin system and energy homeostasis. Trends Endocrinol Metab 1999;10:211-216.

8 Huszar D, Lynch CA, Fairchild-Huntress V, Dunmore JH, Fang Q, Berkemeier LR, Gu W, Kesterson RA, Boston BA, Cone RD, Smith FJ, Campfield LA, Burn P, Lee F: Targeted disruption of the melanocortin-4 receptor results in obesity in mice. Cell 1997;88:131-141.

-9 Gotoh K, Liu M, Benoit SC, Clegg DJ, Davidson WS, D'Alessio D, Seeley RJ, Tso P, Woods SC: Apolipoprotein A-IV interacts synergistically with melanocortins to reduce food intake. Am J Physiol Regul Integr Comp Physiol 2006;290:R202-R207.

-10 Tong Q, Ye CP, Jones JE, Elmquist JK, Lowell BB: Synaptic release of GABA by AGRP neurons is required for normal regulation of energy balance. Nat Neurosci 2008;11:9981000 .
11 Madisen L, Zwingman TA, Sunkin SM, Oh SW, Zariwala HA, Gu H, Ng LL, Palmiter RD, Hawrylycz MJ, Jones AR, Lein ES, Zeng H: A robust and high-throughput Cre reporting and characterization system for the whole mouse brain. Nat Neurosci 2010;13:133-140.

12 Berglund ED, Liu C, Sohn JW, Liu T, Kim $\mathrm{MH}$, Lee CE, Vianna CR, Williams KW, Xu Y, Elmquist JK: Serotonin $2 c$ receptors in proopiomelanocortin neurons regulate energy and glucose homeostasis. J Clin Invest 2013; 123:5061-5070.

13 Pinto S, Roseberry AG, Liu H, Diano S, Shanabrough M, Cai X, Friedman JM, Horvath TL: Rapid rewiring of arcuate nucleus feeding circuits by leptin. Science 2004;304: 110-115.

14 Balthasar N, Dalgaard LT, Lee CE, Yu J, Funahashi $\mathrm{H}$, Williams T, Ferreira M, Tang V, McGovern RA, Kenny CD, Christiansen LM, Edelstein E, Choi B, Boss O, Aschkenasi C, Zhang CY, Mountjoy K, Kishi T, Elmquist JK, Lowell BB: Divergence of melanocortin pathways in the control of food intake and energy expenditure. Cell 2005;123:493-505.
apoA-IV Regulates Melanocortin Neurons
Neuroendocrinology 2016;103:476-488 DOI: $10.1159 / 000439436$ 
15 Cao X, Xu P, Oyola MG, Xia Y, Yan X, Saito $\mathrm{K}$, Zou F, Wang C, Yang Y, Hinton A, Jr, Yan C, Ding H, Zhu L, Yu L, Yang B, Feng Y, Clegg DJ, Khan S, DiMarchi R, Mani SK, Tong Q, $\mathrm{Xu} \mathrm{Y}$ : Estrogens stimulate serotonin neurons to inhibit binge-like eating in mice. J Clin Invest 2014;124:4351-4362.

16 Sohn JW, Harris LE, Berglund ED, Liu T, Vong L, Lowell BB, Balthasar N, Williams $\mathrm{KW}$, Elmquist JK: Melanocortin 4 receptors reciprocally regulate sympathetic and parasympathetic preganglionic neurons. Cell 2013;152:612-619.

17 Liu Y, Liu H, Sauvey C, Yao L, Zarnowska ED, Zhang SC: Directed differentiation of forebrain GABA interneurons from human pluripotent stem cells. Nat Protoc 2013;8:16701679.

18 Liu T, Kong D, Shah BP, Ye C, Koda S, Saunders A, Ding JB, Yang Z, Sabatini BL, Lowell BB: Fasting activation of AgRP neurons requires NMDA receptors and involves spinogenesis and increased excitatory tone. Neuron 2012;73:511-522.
19 Xu Y, Nedungadi TP, Zhu L, Sobhani N, Irani BG, Davis KE, Zhang X, Zou F, Gent LM, Hahner LD, Khan SA, Elias CF, Elmquist JK, Clegg DJ: Distinct hypothalamic neurons mediate estrogenic effects on energy homeostasis and reproduction. Cell Metab 2011;14:453465.

20 Zhu L, Yang Y, Xu P, Zou F, Yan X, Liao L, Xu J, O’Malley BW, Xu Y: Steroid receptor coactivator-1 mediates estrogenic actions to prevent body weight gain in female mice. Endocrinology 2013;154:150-158.

21 Shen L, Pearson KJ, Xiong Y, Lo CM, Tso P, Woods SC, Davidson WS, Liu M: Characterization of apolipoprotein A-IV in brain areas involved in energy homeostasis. Physiol Behav 2008;95:161-167.

22 Yang Y, Atasoy D, Su HH, Sternson SM: Hunger states switch a flip-flop memory circuit via a synaptic AMPK-dependent positive feedback loop. Cell 2011;146:992-1003.
3 Krashes MJ, Shah BP, Madara JC, Olson DP, Strochlic DE, Garfield AS, Vong L, Pei H, Watabe-Uchida M, Uchida N, Liberles SD, Lowell BB: An excitatory paraventricular nucleus to agrp neuron circuit that drives hunger. $\mathrm{Na}$ ture 2014;507:238-242.

24 Atasoy D, Betley JN, Su HH, Sternson SM: Deconstruction of a neural circuit for hunger. Nature 2012;488:172-177.

25 Cone RD: Anatomy and regulation of the central melanocortin system. Nat Neurosci 2005; 8:571-578.

26 Krashes MJ, Shah BP, Koda S, Lowell BB: Rapid versus delayed stimulation of feeding by the endogenously released AgRP neuron mediators GABA, NPY, and AgRP. Cell Metab 2013;18:588-595.

27 Borghini I, Barja F, Pometta D, James RW: Characterization of subpopulations of lipoprotein particles isolated from human cerebrospinal fluid. Biochim Biophys Acta 1995; 1255:192-200. 